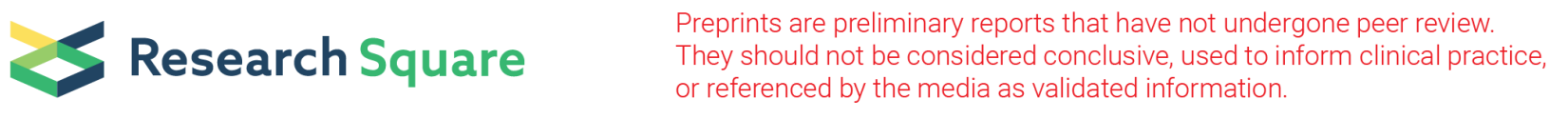

\title{
Effect of structured training programme on knowledge of stakeholders working for Particularly Vulnerable Tribal Groups (PVTGs) in twelve tribal districts of an eastern state of India
}

Vikas Bhatia

All India Institute of Medical Sciences Bhubaneswar

Prajna Paramita Giri ( $\sim$ prajnaparamita.giri@gmail.com )

All India Institute of Medical Sciences Bhubaneswar https://orcid.org/0000-0001-7062-0916

Manish Taywade

All India Institute of Medical Sciences Bhubaneswar

\section{Research article}

Keywords: PVTG, Particularly Vulnerable Tribal Groups, Tribal, Scheduled Tribe, Training, Knowledge assessment

Posted Date: June 9th, 2020

DOI: https://doi.org/10.21203/rs.3.rs-31417/v1

License: (c) (i) This work is licensed under a Creative Commons Attribution 4.0 International License. Read Full License 


\section{Abstract \\ Background}

Particularly Vulnerable Tribal Groups (PVTGs) are the most marginalized tribal communities in the Indian society. The uptake of government led health \& nutrition programme by them is low due to the geographical remoteness of their habitat, communication gap between service providers and PVTGs and their cultural believe. The objective of this study is to implement \& assess the effectiveness of training programmes for stakeholders working for PVTGs in tribal districts of Odisha, an eastern state of India.

\section{Methods}

A cross-sectional study was done in 12 tribal districts during April 2019 to January 2020. Six modules were developed for the trainings of different stakeholders like health officials, officials from Women \& Child Development departments, NGO personnel, functionaries of Odisha Livelihood Mission (OLM) and Odisha PVTG Empowerment \& Livelihood Programme (OPELIP). Three-day residential training programmes covered six thematic areas like child malnutrition, adolescent health, maternal health, communication in service delivery and about different PVTG communities and evaluation was done for 231 participants out of total 242 trained. Pretest and posttest knowledge assessment of the participants were done using a pretested structured questionnaire consisting of 20 items.

\section{Results}

The mean total score of knowledge was significantly improved after training as compared to before training among all stakeholders ( $13.79 \pm 3.78$ vs $11.5 \pm$ 5.2 , p value $=0.001$ ). The pre-test result for the overall knowledge was low among OPELIP staff and health functionaries with mean score of $8.41 \pm 3.03 \& 9.16$ \pm 2.49 respectively. The post-test scores of health functionaries were highest in all domains and the overall increase in knowledge was statistically significant (pre-test $9.16 \pm 2.49$ vs $15.48 \pm 4.19, \mathrm{p}<0.0001)$.

\section{Conclusion}

The assessment of pre \& post test results revealed a significant improvement in knowledge of stakeholders. Hence, there should be administrative mechanism in government system to impart training to all stakeholders at regular intervals.

\section{Background}

The aboriginal ethnic groups or indigenous peoples are culturally distinct societies and communities. Worldwide, approximately 370 million indigenous peoples are residing across some 90 countries, making up 5 percent of the global population [1]. They live in all geographic regions and represent 5,000 different cultures. The aboriginal ethnic groups of India are called "scheduled tribes". As per 2011 Census of India, 705 scheduled tribes (STs), constitutes approximately $8.6 \%$ of India's population [2]. Out of the total Scheduled Tribe population, approximately 2.6 million (2.5 per cent) belong to "Particularly Vulnerable Tribal Groups" (PVTGs). This classification is reserved for the most disadvantages of all the ST communities. PVTGs are distinguished from other tribal communities with regard to their pre-agricultural economy, extremely low level of literacy, isolated habitation etc. [3]. There are 75 identified PVTGs spread across 18 States and Union Territories in India [4]. And among them, Odisha, an eastern state of India with a population of approximately 41.9 million [2] has the distinction of having the largest number of PVTG-13. [5]. The PVTGs in Odisha are scattered over 541 villages in 12 districts of the state with an estimated 83,611 population.

In every part of the world, the aboriginal ethnic groups face discrimination and are forcefully evacuated of their ancestral land by large-scale deforestation, establishment of industries, factories in the name of economic development, which deprive them of their recourses for survival and cultural practices [6-8]. Studies across the globe have shown that the indigenous people experience enormous health disparities compared with the general population [9-14].

The health needs of the indigenous people and the health care utilization trajectory may be met if interventions would have some relevance with their culture. In this context, Government of India implemented the Scheme of "Development of Particularly Vulnerable Tribal Groups (PVTGs)" exclusively for them through the Ministry of Tribal Affairs [15]. Under this scheme, Conservation-cum-Development (CCD) Plan for the PVTGs are to be prepared by each state and Union Territory for their PVTGs. The schemes are implemented by the Scheduled Tribes \& Scheduled Caste Development, Minorities \& Backward Classes Welfare (SSD) Department of the State Government through Micro Projects (registered societies). To ensure focused programme implementation for 13 PVTGs, 17 micro-projects in 542 villages have been established in 12 tribal districts of Odisha [16]. Although significant success has been achieved in reaching many Scheduled Tribes (STs) in Odisha, the PVTG communities remain conspicuously unreached. In this project, we envisaged to do the orientation and training of all the stakeholders in Micro-project areas in twelve districts of Odisha who would be involved in implementation of these initiatives by providing technical support.

We are presenting here the implementation of the training program and results of effectiveness of this training program on knowledge related to childhood malnutrition, adolescent health issues, maternal and child health issues and effective communication among different stakeholders.

\section{Methods And Materials}




\section{Study Design and setting:}

The analysis presented here is a part of the project "Jiban Sampark" which literally means "Connection with Life". This project was envisaged to enhance the uptake of health \& nutrition programmes by the PVTG communities. For generating demand among the PVTGs and to provide quality services to them, the knowledge, skill and attitude of the stakeholders play a vital role. Hence, in collaboration withGovernment of Odisha and UNICEF, All India Institute of Medical Sciences, Bhubaneswar, an Institute of National Importance (INI), provided technical support and capacity building of different stakeholders working in 17 micro-project areas in 12 tribal districts (Fig-1). The details of the micro-project areas and PVTGs have been given in table-1. These trained stakeholders would be involved in implementation of government led programmes and schemes and they in turn would train the front line workers (FLW) like ASHA (Accredited Social Health Activist) who work for population of 1000 at village level on honorarium basis, ANM (Auxillary Nurse Midwife) a frontline worker from Health \& Family Welfare (H\&FW) Department, AWW (AnganWadi Workers) a frontline worker of Women \& Child Development (WCD) Department, local leaders, traditional healers who could influence the PVTG communities. The trainings were conducted during April 2019 to January 2020.

\section{Participants:}

The participants were the stakeholders include health officials, officials from Women \& Child Development departments like Child Development Programme Officers (CDPOs), supervisors of Integrated Child Development Services Scheme (ICDS), NGO personnel, Special Project Officers, functionaries of Odisha Livelihood Mission (OLM) and Odisha PVTG Empowerment \& Livelihood Programme (OPELIP).

Trainings \& Training methods:

Intensive three-day residential trainings for stakeholders like functionaries of OLM \& OPELIP, NGO functionaries, ICDS supervisors, health functionaries (Public Health Extension Officers) who would be Master Trainers for further training of Front-Line Workers in the field were taken up during the time period from April 2019 to January 2020. The trainings were organized in phase-wise manner. A pool of 242 master trainers was created through 6 batches of 3-day training over this period.

This training covered various aspects related to adolescent health, antenatal \& postnatal care, maternal \& child health, malnutrition among under-5 children and communication. Six modules were developed by the researchers and vetted by the experts in the respective field. These modules were used for training. Lecture, Group discussion, Group activities, practical demonstration (how to measure weight, height, Mid-arm Circumference), role play (for communication) were the different methods used in training. These modules were given to the participants for further reading. A comprehensive module covering all the above thematic areas was developed for the Frontline workers and this was translated to local language.

We are presenting here the implementation of the training program and results of effectiveness of this training program on knowledge related to adolescent health, maternal and child health issues, communication methods among different stakeholders.

\section{Outcome assessment}

Pretest and posttest evaluation for knowledge assessment of the participants were done using a pretested structured questionnaire consisting of 20 items with four questions each from adolescent health, child malnutrition, new-born care \& immunization, antenatal \&post-natal care and communication respectively. The evaluation was done on 231 participants.

\section{Statistical analysis}

The data was analyzed using SPSS version 20.0. Normality of data was assessed using the statistical tests of normality like Shapiro-Wilk and KolmogorovSmirnov tests. Continuous variables with a normal distribution were presented as the mean \pm standard deviation (SD) and qualitative data was expressed with frequency and percentages. Pre and post test score of an individual question as well as for a particular domain or thematic area was assessed using McNamara's test and comparison of cumulative pretest score and post test score was analyzed using paired t test. Comparison of mean values of pretest and post test score of different groups was analyzed using Analysis of Variance and p value less than 0.05 was considered to be statistically significant.

\section{Results}

A total of 242 participants were trained in 6 numbers of ToTs (Training of Trainers). Male participants constituted $52 \%$ and females $48 \%$. A total of 58 (23.9\%) NGO functionaries, 24 (9.9\%) OLM officials, 35 (14.0\%) OPELIP officials, 81 (33.5\%) ICDS supervisors and 45 (18.6\%) health functionaries were trained (Fig-2). But analysis was done for 231 participants as six NGO functionaries repeated the training in subsequent batches and five participants either missed the pre or post-test sessions, they were excluded. Questions were based on five domain or thematic areas such as childhood malnutrition, adolescent health, antenatal and postnatal care, New-born care \& immunization and communication. Each area contains 4 questions. The knowledge of participants was assessed by using pretested structured questionnaire. There was significant improvement in knowledge in different domains after training. The pretest results for communication in service delivery (44.04\%) and new-born care \& child immunization (46.7\%) was relatively low but that of adolescent health was highest (52.4\%). There was significant improvement in knowledge in all the domain/thematic area after training. The mean total score of knowledge was significantly improved (13.79 \pm 3.78$)$ after training as compared to before training (11.5 \pm 5.2$)$ (Table-2).

A comparison between knowledge of different stakeholders in different domains was done (Table-3 \& Fig-3). The pre-test result for the overall knowledge was low among OPELIP staff and health functionaries with mean score of $8.41 \pm 3.03 \& 9.16 \pm 2.49$ respectively. But in post-test results, the highest score was obtained by the health functionaries $(15.48 \pm 4.19)$ followed by OLM staff $(14.91 \pm 3.26)$. In all the domains, the health functionaries had scored better than

Page $3 / 10$ 
the staff of other department except for communication in service delivery, where the NGO functionaries had scored highest. Among all the stakeholders there was significant increase in the level of knowledge between pre-test and post-test results.

The knowledge of OPELIP staff was lower than any other stakeholders in every domain except for WCD functionaries whom knowledge was lowest in communication. The knowledge gap between the stakeholders of different categories in all domains was larger in pre-test results as compared to the post-test results.

\section{Discussion}

The uptake of health \& nutrition programme by the PVTGs is very low. Cultural factors followed by the long distance to cover owing to the geographical remoteness and belief in indigenous system of treatment explain most of the reasons for non-utilization. Significant mistrust between tribal communities and service providers who are largely non-tribal, weak demand and non-responsive supply chain become barrier for the planners, programmers and functionaries in delivering the health care services to the PVTGs. Hence the interventions to enhance the uptake of different health \& nutrition related programme by PVTGs should be sensitive enough to have some relevance to their culture. There is huge cultural difference among the PVTGs also. So, a particular approach that works for one PVTG will not work for others. Programmes should be designed according to their need and cultural context. Functionaries of different departments working closely with these PVTGs need to understand the intricacies of their culture as well as the technical stuff to render help to these communities at the time of need. Hence, training of these functionaries becomes necessary to build their capacity.

The present study was carried out to provide technical support and capacity building of different stakeholders working closely with the PVTG communities in 12 districts of Odisha. Through six intensive training programmes, 242 stakeholders were trained to be master trainers for the frontline workers.

In this study, the mean total score was significantly improved after training as compared to before training among all stake holders ( $13.79 \pm 3.78$ vs $11.5 \pm 5.2$, $\mathrm{p}$ value $=0.001)$. Study conducted by Nelson BD et al on frontline maternal, newborn, and child health workers in South Sudan observed that the scores improved significantly from $62.7 \% \pm 20.1 \%$ pre-training to $92.0 \% \pm 11.8 \%$ post training (p value $<0.001)[17]$

The pre-test result for the overall knowledge was low among OPELIP staff with mean score of $8.41 \pm 3.03$. As OPELIP staffs are involved more in livelihood programmes like agriculture, horticulture, fisheries, animal husbandries etc, they have less technical knowledge in the field of health and nutrition. On the contrary, the knowledge in OLM staff was quite good with mean score of $11.41 \pm 3.42$ even though their exposure to health \& nutrition technicality is similar to OPELIP staff. The pre-test findings for health functionaries (Public Health Extension Officers) were strangely lower (Mean score 9.16 \pm 2.49 ) than other stakeholders except OPELIP staff. But, the post-test scores of health functionaries were highest in all domains and the overall increase in knowledge was statistically significant (pre-test $9.16 \pm 2.49$ Vs $15.48 \pm 4.19, p<0.0001$ ). A study conducted by Khyati FN et el, amongst community health workers in Indonesia documented a significant improvement in knowledge regarding management of children with cough and breathing difficulties amongst those were trained ( $p$ value $<0.05$ )[18]As ICDS supervisors work mostly for under-5 children, their knowledge in child malnutrition was better than other stakeholders in pre-test assessment and there was significant improvement in knowledge after the training. But their knowledge was low in the domain of communication in service delivery. This may be due to their less direct interaction with the beneficiaries like under-5 children and mothers. The knowledge regarding new-born care (kangaroo mother care) and immunization was improved significantly from 46.7-75\%. Similar findings were observed by Batra $\mathrm{K}$ et al where in the post test the participants improved their score to $100 \%$ [19]. The study by Tawfiq E et el have also shown that regular training of health care workers can improve quality of care of under-5 children [20]. Inservice and pre-service trainings are required by the stakeholders working in the field of nutrition and health as these are ever evolving subjects. A study by Ameh et el recommended in-service \& pre-service emergency obstetric and new-born care training for health care providers for better maternal health outcomes. But these emergency obstetric and new-born care trainings are lengthy and more intensive than the trainings we conducted for the stakeholders [21]. Study conducted by Bredfelt et el have found that training improved electronic health records (EHRs) skills of health care providers. The training sessions consisted of short lectures and demonstrations (20-40 minutes) were interspersed with hands-on directed activity. The training methods were similar to ours but the duration of training was shorter in their case. Another plus point in their trainings were that, those were conducted in live HER environment which might have resulted in better results in terms of outcome [22].

The strength of this study was that it was a first of its kind of training for the stakeholders working for PVTG communities in 12 tribal districts of Odisha and also assessed the usefulness of the training modules specifically developed for this training. The training module had covered all the aspects of child health, adolescent health, maternal health, communication strategies in service delivery and evaluated for the same. This training would equip the stakeholders with the required knowledge and skill to deliver quality health \& nutrition services to the PVTGs and as Front-Line Workers (FLWs), local leaders and traditional healers would be trained subsequently, the communication gap between the PVTGs and non-tribal service providers would be filled up. The project has a component of monitoring of the trainings of FLWs. Hence the rolling out of the programme would be reinforced and quality of training would be good. Assessment of the participants immediately post training which might have resulted in an increase in the level of knowledge regarding different components of maternal and child health may be a limitation for the study.

\section{Conclusion}

Under Universal Health Coverage, provision of health services for all is the mandate of both state and central government. As the Particularly Vulnerable Tribal Groups (PVTG) are the most marginalized social category in India, many health \& nutrition related programmes by state \& central government are intended for them. But the uptake of these programmes by them is very low due to various factors. All the stakeholders working for PVTGs play crucial role in increasing the uptake of these programme by these communities. In this study, technical support and capacity building was provided to most of the stakeholders working in the tribal districts of Odisha where most of the PVTGs are residing. Significant increment in knowledge was observed for almost all domains and among all 
categories of stakeholders following trainings. As these master trainers would train the frontline workers in their respective areas, it is suggested that, there should be refresher trainings for these stakeholders at regular intervals to maintain the knowledge level.

\section{Abbreviations}

PVTGs

Particularly Vulnerable Tribal Groups

ASHA

Accredited Social Health Activist

WCD

Women \& Child Development departments

ICDS

Integrated Child Development Scheme

NGO

Non-Government Organization

OLM

Odisha Livelihood Mission

OPELIP

Odisha PVTG Empowerment \& Livelihood Programme (OPELIP).

UNICEF

United Nations Children's Fund

GP

Gram Panchayat (A Gram Panchayat is the local self-government organization in India of the Panchayati Raj system, at the village level)

\section{Declarations}

\section{ETHICS APPROVAL AND CONSENT TO PARTICIPATE:}

Approved by. IEC-All India Institute of Medical Sciences, Bhubaneswar

Ethical Approval Number T/EM-F/ CM\&FM/17/22 dated 11 1 th December 2017

Consent to participate: Verbal consent was taken from the participants as pre-test sessions, post-test sessions and taking feedback about the training (Methods of training, Material used, timing, resource persons etc) were the part of these trainings (mentioned in the main protocol submitted to the IEC). Therefore, we did not take separate informed consent from the participants for pre-test and post-test sessions.

\section{CONSENT TO PUBLISH:}

Authors give their consent to publish

\section{AVAILABILITY OF DATA AND MATERIALS:}

There is mutual understanding between the funding agency (UNICEF, Bhubaneswar, Odisha) and AlIMS, Bhubaneswar not to share the raw data with anyone. Apart from NGO functionaries, all other stakeholders are government employees. So authors cannot share the data with anybody except state government.

\section{COMPETING INTERESTS:}

None declared

\section{FUNDING:}

This program implementation was supported by United Nations Children's Fund (UNICEF).

\section{AUTHORS' CONTRIBUTIONS}

VB, PPG and MT conceived and designed the study. PPG and VB acquired and analyzed the data and prepared the initial manuscript. PPG, VB revised the draft critically. All authors have read and approved the final manuscript. All authors agree to be accountable for all aspects of the work in ensuring that questions related to the accuracy or integrity of any part of the work are appropriately investigated and resolved.

\section{ACKNOWLEDGEMENTS:}

We are thankful to UNICEF and Government of Odisha for their support in Jiban Sampark Project. We are thankful to all resource persons and Senior Residents of the Department of Community Medicine \& Family Medicine, AllMS, Bhubaneswar, for their contribution towards this project. We are thankful to all the participants of this study. We are also thankful to Mr. Manoj Sathpathy (Project Coordinator), Ms Smiti Suhani Senapati (DEO), for their support in the Jiban Sampark project 


\section{References}

1. The Indigenous World 2019. https://www.iwgia.org/images/documents/indigenous world/IndigenousWorld2019_UK.pdf. Accessed on $8^{\text {th }}$ May 2020

2. http: // www.censusindia.gov.in / 2011. Accessed on $10^{\text {th }}$ April 2020

3. Tribal population in India. Tribal Health Bulletin, Vol.20 (Special Issue), January 2014

4. Statistical Profile of Schedule Tribes in India-2013. Ministry of Tribal Affairs, Statistical division, Govt. of India. http: // www.tribal.nic.in.Accessed on 20th April 2020.

5. Ota, A. B., Mohanty, S. C., Sahoo, T., \& Mohanty, B. N. (2008). Primitive tribal groups of Orissa: A handbook. PTGs: Series-V. Bhubaneswar: SCSTRTI. ISBN$81-902819$

6. Das A, Saha A. Status of food security entitlements across Particularly Vulnerable Tribal Group (PVTG) pockets in Jharkhand. BMJ Glob Health 2016;1(Suppl 1): A2-A43

7. United Nations. State of the World's Indigenous Peoples. United Nations Department of Economic and Social Affairs, Secretariat of the Permanent Forum on Indigenous Issues, editor. New York 2009 https://www.un.org/esa/socdev/unpfii/documents/SOWIP/en/SOWIP_web.pdf

8. Language Vitality and Endangerment. UNESCO

9. Kitching GT, Firestone M, Schei1B Wolfe S, Bourgeois C, O'Campo P, RotondiM et el. Unmet health needs and discrimination by healthcare providers among an Indigenous population in Toronto, Canada. Can J Public Health (2020) 111:40-49

10. Markwick A, Ansari Z, Clinch D and McNeil J. Experiences of racism among Aboriginal and Torres Strait Islander adults living in the Australian state of Victoria: a cross-sectional population-based study. BMC Public Health (2019) 19:309

11. Allan B, Smylie J. First peoples, second class treatment: the role of racism in the health and well-being of indigenous peoples in Canada. Toronto: Wellesley Institute; 2015.

12. Wylie L \&McConkey S. Insiders' Insight: Discrimination against Indigenous Peoples through the Eyes of Health Care Professionals. Racial and Ethnic Health Disparities (2019) 6:37-45

13. Cerón A, Ruano1 AL, Sánchez S, Chew AS, Díaz D, Hernández A and FloresW. Abuse and discrimination towards indigenous people in public health care facilities: experiences from rural Guatemala. International Journal for Equity in Health (2016) 15:77

14. Gandhi S, Verma VR, Dash U. Health seeking behaviour among particularly vulnerable tribal groups: A case study of Nilgiris. Public Health Epidemiol. Vol. 9(4), pp. 74-83, April 2017.

15. Press Information Bureau. Government of India. Ministry of Tribal Affairs. 21-December-2015 ITDA and Micro Projects https://pib.gov.in/newsite/PrintRelease.aspx?relid=133666. Accessed on $25^{\text {th }}$ April 2020

16. Annual Activity Report: 2018-19.ST \& SC Development, Minorities \& Backward Classes Welfare Department, Govt. of Odisha. http://www.stscodisha.gov.in/pdf/SSD_Annual_Activity_Report-2018-2019.pdf. Accessed on $8^{\text {th }}$ May 2020.

17. Nelson BD, Ahn R, Fehling M, Eckardt MJ, Conn KL, El-bashir A, et al. Evaluation of a novel training package among frontline maternal, newborn, and child health workers in South Sudan. Int J Gynecol Obstet [Internet]. 2012;119:130-5. Available from: https://www.ncbi.nlm.nih.gov/pubmed/22944212. Accessed on $12^{\text {th }}$ May 2020.

18. Khayati FN, Haryanti F, Laksnawati IS. The impact of training on the management of children with cough of the health workers ' knowledge, attitude and skills in the management of children with cough and breathing difficulties. Int J Res Med Sci [Internet]. 2015;3(s1):s47-s52. Available from: msjonline.org/index.php/ijrms/article/download/2543/2411. Accessed on $12^{\text {th }}$ May 2020.

19. Batra K, Mamta. Effectiveness of structured teaching protocol on knowledge related to Kangaroo mother care among staff nurses . Nurs Midwifery Res J [Internet]. 2014;10(3):100-5. Available from: http://medind.nic.in/nad/t14/i3/nadt14i3p100.pdf

20. Tawfiq E, Alawi SAS, Natiq K.Effects of Training Health Workers in Integrated Management of Childhood Illness on Quality of Care for Under-5 Children in Primary Healthcare Facilities in Afghanistan. Int J Health Policy Manag 2020, 9(1), 17-26

21. A. Ameh, N. van den Broek. Making It Happen: Training health-care providers in emergency obstetric and new-born care. Best Practice \& Research Clinical Obstetrics and Gynaecology. 29 (2015) 1077-91

22. Bredfeldt CE, AwadEB,Joseph K, Synder MH. Training providers: beyond the basics of electronic health records. BMC Health Services Research 2013, 13:503.

\section{Tables}

Table-1: Details of the Districts and Micro-project area for implementation of the project. 


\begin{tabular}{|c|c|c|c|c|c|c|c|}
\hline SI No & Districts & Micro-projects & Part of block covered & PVTG & No of GPs & No of Villages & Population \\
\hline 1 & Anugul & P B D A, Jamardihi & Pallahara & PaudiBhuyan & 4 & 25 & 5823 \\
\hline \multirow[t]{3}{*}{2} & \multirow[t]{3}{*}{ Deogarh } & \multirow[t]{3}{*}{ P B D ARugdakudar } & \multirow[t]{3}{*}{ Barkote } & \multirow[t]{3}{*}{ PaudiBhuyan } & 5 & 22 & 4126 \\
\hline & & & & & 4 & 25 & 5823 \\
\hline & & & & & 8 & 32 & 3830 \\
\hline \multirow[t]{2}{*}{3} & \multirow[t]{2}{*}{ Gajapati } & S D A, Chandragiri & Mohana & Saora & 10 & 32 & 5553 \\
\hline & & L S D A, Seranga & Gumma & LanjiaSaora & 3 & 21 & 5553 \\
\hline 4 & Ganjam & T D A, Tumba & Patrapur & Saora & 3 & 58 & 4315 \\
\hline 5 & Kalahandi & KKDA, Lanjigarh & Lanjigarh & KutiaKondh & 3 & 16 & 2683 \\
\hline 6 & Kandhamala & KKDA, Belgarh & Tumudibandha & KutiaKondha & 3 & 68 & 5953 \\
\hline 7 & Keonjhar & JDA, Gonasika & Banspal & Juang & 6 & 35 & 8592 \\
\hline \multirow[t]{4}{*}{8} & \multirow[t]{4}{*}{ Malakanagiri } & BDA & Khairaput & Bonda & 4 & 30 & 6676 \\
\hline & & Mudulipada & & & & & \\
\hline & & DDAK & K.Gumma\&Khairaput & Didayi & 4 & 37 & 7250 \\
\hline & & Guma & & & & & \\
\hline \multirow[t]{3}{*}{9} & \multirow[t]{3}{*}{ Mayurbhanja } & LDA, Moroda & Suliapada\&Moroda & Lodha & 8 & 12 & 3112 \\
\hline & & \multirow[t]{2}{*}{ HK \& MDA, Jhasipur } & Karanjia & Hill Khari, & 12 & 18 & 2111 \\
\hline & & & \&Jashipur & Mankird, Birhor & & & \\
\hline 10 & Nuapada & CBDA, Sonabeda & Komna & ChuktiaBhunjia & 3 & 14 & 2378 \\
\hline \multirow[t]{3}{*}{11} & \multirow[t]{3}{*}{ Rayagada } & DKDA, Parssali & K.singhpur & DongriaKondha & 2 & 39 & 2584 \\
\hline & & DJDA, Chatikona & BisamKatak\&Muniguda & DongriaKondha & 5 & 62 & 6264 \\
\hline & & LSDA,Puttasing & Gunupur & LanjiaSaora & 1 & 20 & 6267 \\
\hline 12 & Sundergarh & PBDA, Khutgan & Lahunipada & PaudiBhuyan & 5 & 22 & 4162 \\
\hline Tot-al & 12 & 17 & 20 & 13 & 84 & 541 & 83,611 \\
\hline
\end{tabular}

Table-2: Assessment of knowledge in different domains before \& after training

\begin{tabular}{|lllll|}
\hline Domains & Pretest Correct Response (\%) & Post-test Correct Response (\%) & McNemar Test Statistic & P value \\
\hline Child Malnutrition & $476(51.5)$ & $571(61.9)$ & 5.12 & $<0.0001$ \\
\hline Adolescent Health & $484(52.4)$ & $686(74.2)$ & 8.743 & 10.275 \\
\hline New-born Care \& Immunization & $432(46.7)$ & $695(75.2)$ & 10.658 & $<0.0001$ \\
\hline Antenatal \& Postnatal Care & $439(47.5)$ & $700(75.7)$ & 6.528 & $<0.0001$ \\
\hline Communication in service delivery & $407(44.0)$ & $531(57.5)$ & Std. Deviation & 5.19 \\
\hline
\end{tabular}

Table-3: Difference in pre-test\& post-test score of stakeholders in different domains 


\begin{tabular}{|c|c|c|c|c|c|c|c|c|c|c|c|c|c|c|c|c|}
\hline & \multicolumn{3}{|c|}{ Child Malnutrition } & \multicolumn{3}{|c|}{ Adolescent Health } & \multicolumn{3}{|c|}{$\begin{array}{l}\text { New-borm care \& } \\
\text { immunization }\end{array}$} & \multicolumn{3}{|c|}{ ANC \& PNC } & \multicolumn{3}{|c|}{$\begin{array}{l}\text { Communication in } \\
\text { service delivery }\end{array}$} & \multirow{2}{*}{$\begin{array}{l}\text { Total } \\
\text { Pre }\end{array}$} \\
\hline & $\begin{array}{l}\text { Pre- } \\
\text { test }\end{array}$ & Post & $\mathrm{p}$ & Pre & Post & $\mathbf{p}$ & Pre & Post & $\mathbf{p}$ & Pre & Post & $\mathbf{p}$ & Pre & Post & $\mathbf{p}$ & \\
\hline & Mean & $\begin{array}{l}\text { test } \\
\text { Mean }\end{array}$ & & $\begin{array}{l}\text { test } \\
\text { Mean }\end{array}$ & $\begin{array}{l}\text { test } \\
\text { Mean }\end{array}$ & & $\begin{array}{l}\text { test } \\
\text { Mean }\end{array}$ & $\begin{array}{l}\text { test } \\
\text { Mean }\end{array}$ & & & & & & & & \\
\hline & (SD) & (SD) & & (SD) & (SD) & & (SD) & (SD) & & (SD) & (SD) & & (SD) & (SD) & & (SD) \\
\hline \multirow[t]{2}{*}{ NGO } & 2.06 & 2.80 & \multirow{2}{*}{ <. 001} & 2.08 & 2.77 & \multirow{2}{*}{$\hat{0}_{0.001}$} & 1.93 & 2.84 & \multirow{2}{*}{ <. 001} & 1.88 & 2.95 & \multirow{2}{*}{$\overleftarrow{0}_{0.001}$} & 2.04 & 2.66 & \multirow{2}{*}{$\hat{0.001}$} & 10.02 \\
\hline & $(1.07)$ & $(1.09)$ & & $(0.94)$ & $(0.99)$ & & $(0.86)$ & $(0.97)$ & & (1.17 & 1.08 & & 1.16 & 1.14 & & 2.80 \\
\hline \multirow[t]{2}{*}{ OLM } & 2.08 & 2.83 & \multirow[t]{2}{*}{0.003} & 2.29 & 3.29 & \multirow[t]{2}{*}{0.001} & 2.29 & 3.29 & \multirow[t]{2}{*}{0.001} & 2.45 & 3.00 & \multirow[t]{2}{*}{0.010} & 2.29 & 2.50 & \multirow[t]{2}{*}{0.180} & 11.41 \\
\hline & 1.01 & 1.23 & & 0.95 & 0.90 & & 0.95 & 0.90 & & 1.10 & 0.97 & & 0.95 & 0.93 & & 3.42 \\
\hline \multirow[t]{2}{*}{ OPELIP } & 1.64 & 2.11 & \multirow[t]{2}{*}{0.007} & 1.61 & 2.70 & \multirow{2}{*}{$\dot{0} 001$} & 1.61 & 2.94 & \multirow{2}{*}{$\dot{0} 001$} & 1.79 & 2.85 & \multirow{2}{*}{$\dot{0} 001$} & 1.73 & 2.38 & \multirow[t]{2}{*}{0.006} & 8.41 \\
\hline & 1.04 & 1.29 & & 0.88 & 1.03 & & 1.10 & 1.25 & & 0.94 & 1.10 & & 1.26 & 1.10 & & 3.03 \\
\hline \multirow[t]{2}{*}{ WCD } & 2.36 & 2.10 & \multirow[t]{2}{*}{0.039} & 2.35 & 2.87 & \multirow[t]{2}{*}{0.002} & 1.87 & 2.83 & \multirow{2}{*}{$\dot{0} 001$} & 1.75 & 3.01 & \multirow{2}{*}{$<.001$} & 1.45 & 2.00 & \multirow[t]{2}{*}{0.001} & 14.85 \\
\hline & 0.99 & 0.93 & & 1.07 & 1.21 & & 0.96 & 1.42 & & 1.19 & 1.33 & & 1.17 & 1.27 & & 6.37 \\
\hline \multirow[t]{2}{*}{ Health } & 1.76 & 3.04 & \multirow{2}{*}{ ¿.001 } & 1.86 & 3.39 & \multirow{2}{*}{$\hat{0.001}$} & 1.76 & 3.41 & & 1.97 & 3.30 & & 1.79 & 2.32 & & 9.16 \\
\hline & 0.92 & 1.02 & & 0.96 & 1.17 & & 0.94 & 1.19 & & 0.96 & 0.86 & & 0.94 & 1.01 & & 2.49 \\
\hline Total & 2.06 & 2.49 & $<001$ & 2.09 & 2.97 & $<001$ & 1.87 & 3.00 & & 1.90 & 3.03 & 0001 & 1.76 & 2.29 & $<$ & 11.55 \\
\hline & 1.03 & 1.14 & & 1.02 & 1.13 & & 0.96 & 1.24 & 0.00 & 1.11 & 1.13 & 0.001 & 1.14 & 1.16 & & $(5.19)$ \\
\hline
\end{tabular}

\section{Figures}

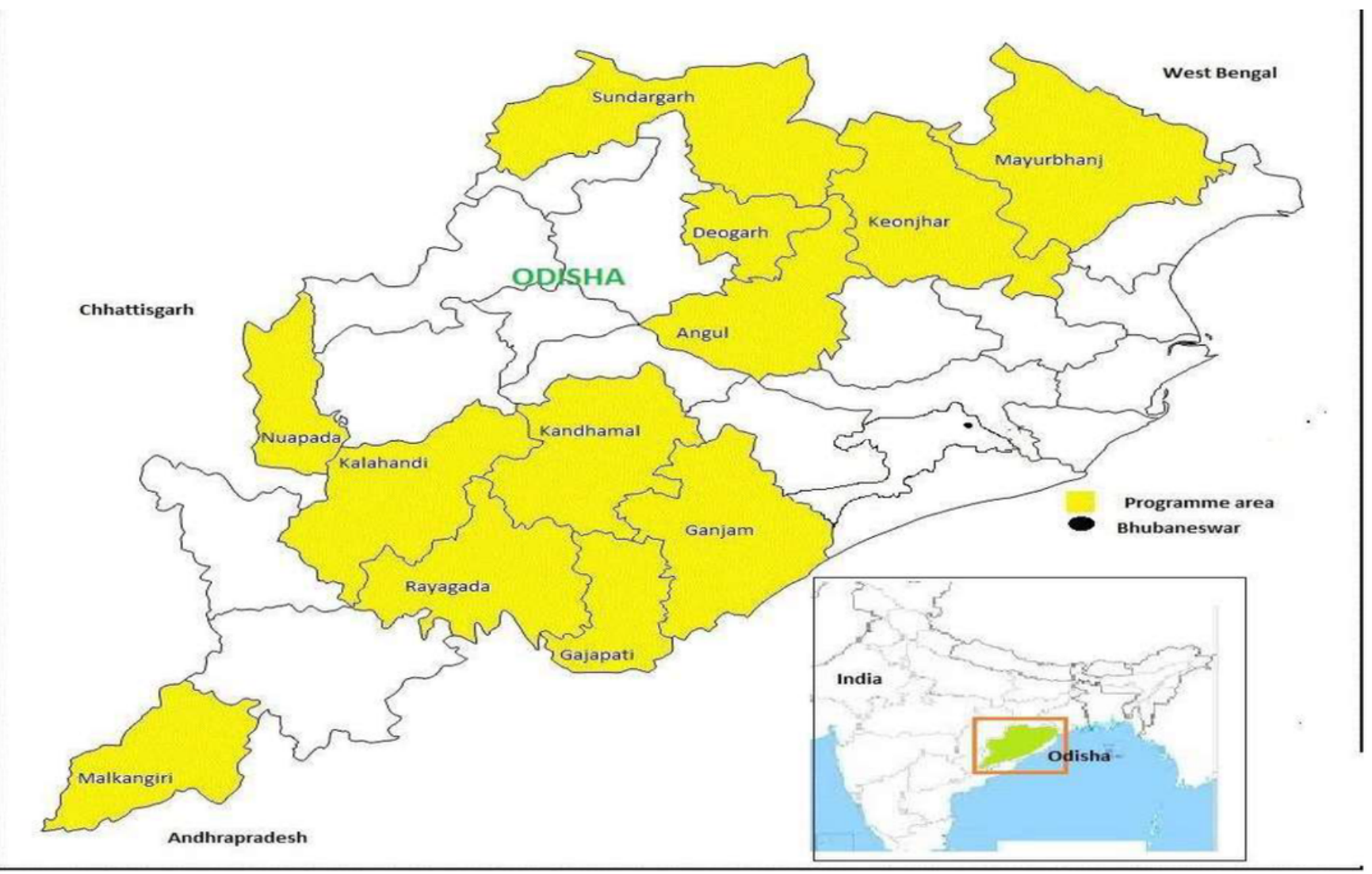

Figure 1

Twelve districts of Odisha having PVTG and implementation of Project This figure has been created by me (PPG). URL: https://www.google.com/search? $q=$ odisha+map+blank\&rlz=1C1GIWA_enIN881IN881\&sxsrf=ALeKk012vYhtIIPMMouRZjI4tFgZIdYwqw:1590483635503\&tbm=isch\&source=iu\&ictx=1\&fir=fJWtI kT_9yD7Mm87PFWRrmpUxXtINcW_fA\&sa=X\&ved=2ahUKEwjEOfWgldHpAhVMzDgGHdeMD_kQ9QEwA3oECAoQIg\#imgrc=fJWtUQgjK2_ziM: Software used: Microsoft Paint (version 6.1) 


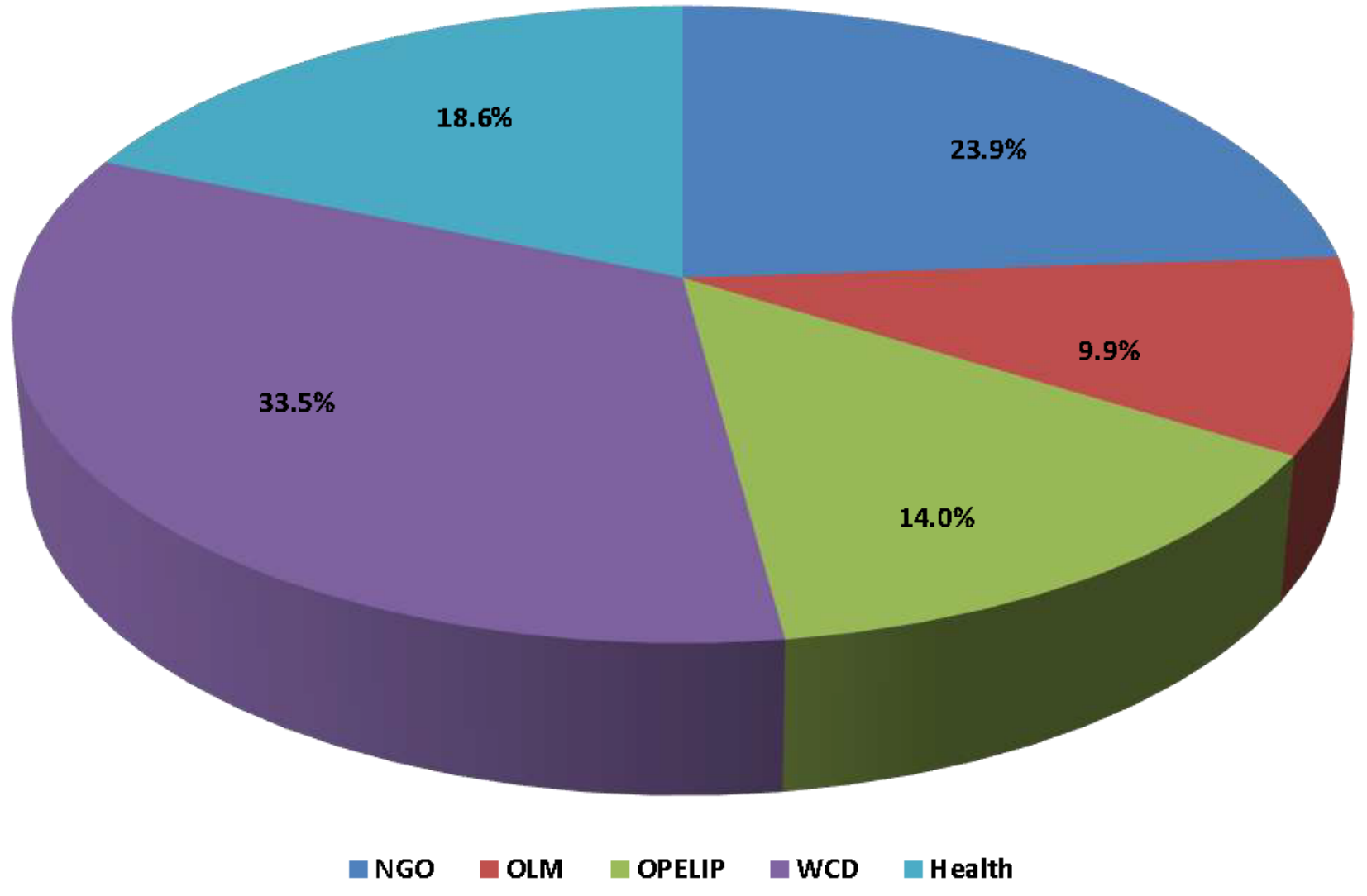

Figure 2

Participants from different departments \& NGOs 


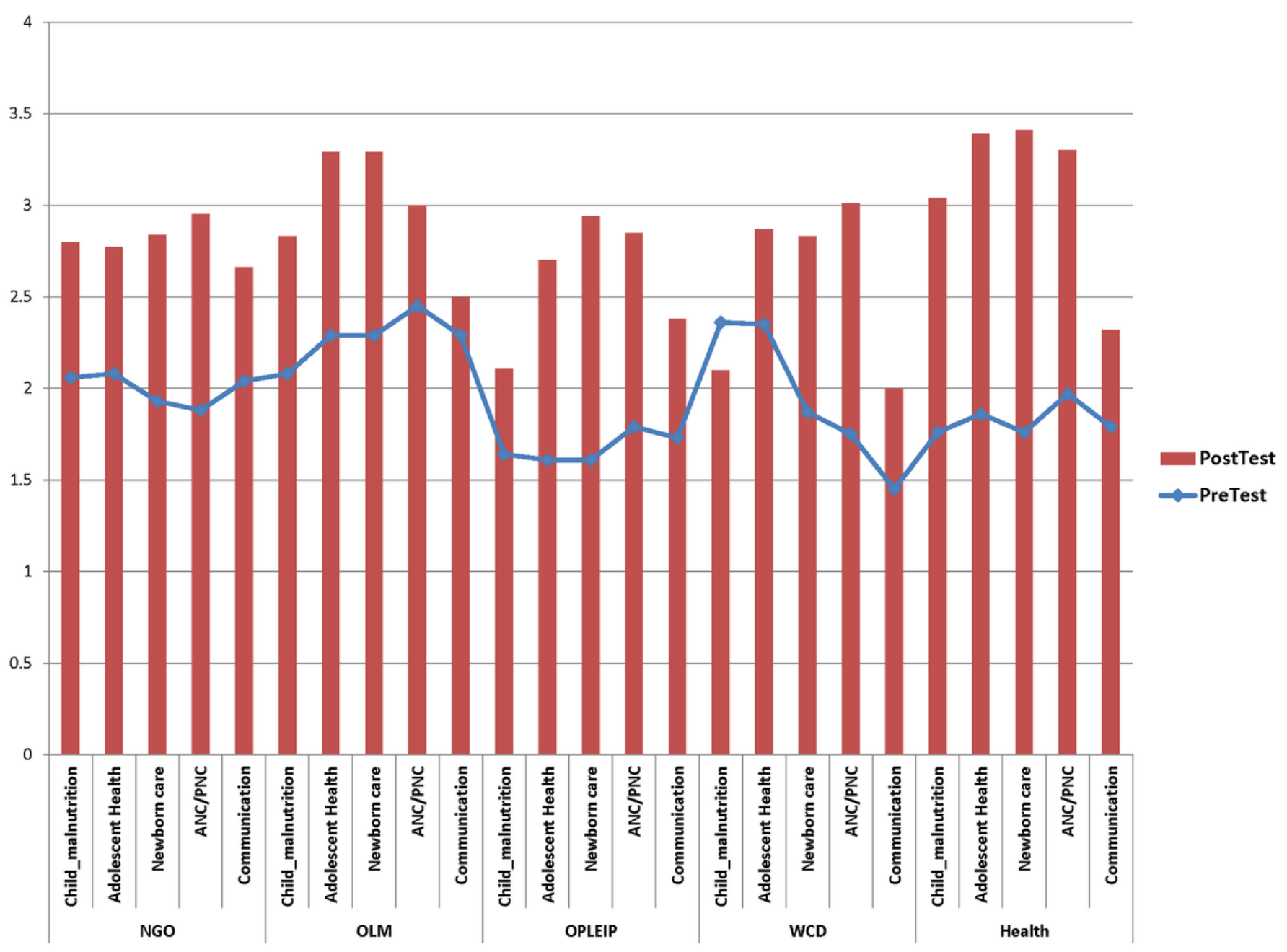

Figure 3

Pre-test \& Post-test Scores of different stakeholders 